\title{
Exposed patients: a reflection on confidentiality, narcissism and bioethics education
}

\footnotetext{
1 Coordenadora do Comitê de Bioética do Hospital Materno-Infantil Presidente Vargas da Secretaria Municipal de Saúde de Porto Alegre HMIPV/SMS/PMPA, Porto Alegre, RS, Brasil. 2 Laboratório de Pesquisa em Bioética e Ética na Ciência, Hospital de Clínicas de Porto Alegre - HCPA, Porto Alegre, Rio Grande do Sul, Brasil
}

Physicians pose proudly next to their patients online. They expose patients to lay audiences without taking care to hide identifiable data. They comment on medical information on social networks. ${ }^{1}$ The duty of secrecy or confidentiality is often neglected in everyday practice. Is that due to narcissism, deficiencies in self-regulation or in education? The goal here is not to pass judgment but to remember the importance of reflecting on these aspects in professional practice, since this can cause embarrassment to the patients, influence colleagues, in addition to leading to ethical and judicial procedures. Beginners or experts, physicians can eventually forget about patient privacy, possibly due to gaps in training. But learning and incorporating ethical and bioethical principles in professional practice require, in addition to information, some maturity. These are linked to the notion of identity, responsibility, and otherness, ${ }^{2}$ to the limits between the Self and the Other, to the respect the patient's individuality.

Unfortunately, the importance of psychosocial and emotional development has often been neglected over the course of training, and, not infrequently, during professional life. The maintenance of balance and coping with the crisis inherent to the different stages of life require a combination of capabilities that are developed since childhood, depending on the interaction with the environment to which the child is exposed. The ability to regulate emotions, thoughts, and behaviors is built through a complex process that involves multiple domains and skills. ${ }^{3}$ Childhood experiences shape their functioning later in life, influencing learning and communication skills. Using a psychoanalytical referential, narcissism refers to the period of development during which the baby still does not recognize the existence of others (the mother or her substitute). This recognition of the self and others happens gradually, under normal circumstances, throughout childhood and adolescence and continues in a dynamic process throughout life. When people have gaps in early development, in the integration of the self or self-image, and on the so-called individuation, the search for "narcissistic" compensation can become, unconsciously, a strategy for psychic

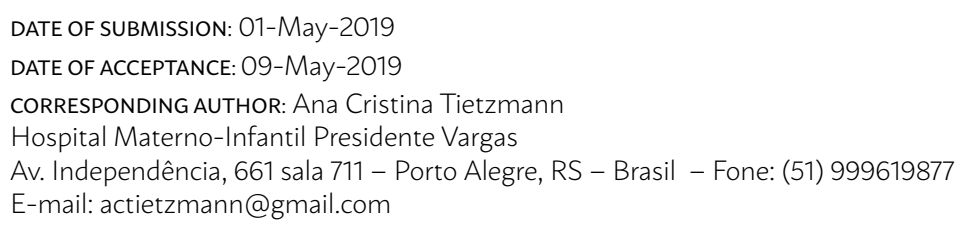


survival. A self-centered functioning and "satisfaction at any cost" can have harmful consequences. Some people have greater difficulties, such as high intolerance to frustration and diverse interpersonal problems. ${ }^{4} \mathrm{How}$ ever, a "dose" of narcissism is also necessary for the well-being. To have one's effort and skills recognized generates joy and enhances self-esteem. "Healthy narcissism" brings satisfaction through learning and developing skills. The social value of the medical profession and work can stimulate growth. But, on the search for professional recognition and admiration, one should avoid the potential pitfalls of narcissistic seduction that the relationship with the patients may present. Healthy narcissism takes into account the needs of others. Maturity makes it possible to understand when the other is in search of narcissistic rewards and assess its adequacy in the relationship. If the patient decides to post a photo with the physician on a social network, provided the physician agrees, there is no problem. It is the physician who is prevented from taking this type of action due to professional confidentiality.

The therapeutic relationship is based on trust and the patient's belief that physicians will do what is best for their patients. From this confidence comes the duty of confidentiality. The duty to safeguard and not disclose, to those who do not need to know, information, images, and data obtained during the exercise of the profession. Even if the patient, or their representative, authorize it. Even if the person is already deceased or no longer a patient. The duty of secrecy has been present from classical antiquity, with the Hippocratic oath, until the present time, with the recently updated Code of Medical Ethics. The moral code that governs medical practice does not exist by accident. It protects the professional and patients of abuse and reinforces fundamental values and rights. In this case, the respect for persons and the right to privacy. ${ }^{5}$ Physicians must not forget to respect the privacy of the patient. They cannot publicly expose, or to lay audiences, information, and images of patients without hiding identifiable data. In academic environments and healthcare institutions, all professionals, employees, and students have a duty of confidentiality associated with the clinical information to which they have access. Even though these values appear to be in disuse nowadays, they are required in healthcare professions. And there is no point in whining.

Handling frustration and uncertainty requires effort and maturity. Clinical practice is full of such challenges. Valuing opportunities that promote psychosocial development is fundamental throughout the medical career. The individual search for treatments, psychotherapies, and other forms of personal growth can improve the capacity for reflection and interpersonal relationships within and outside the work environment. Stimulating educational environments can contribute to new learnings in all stages of life. Within healthcare institutions, Clinical Bioethics committees can have an important role in bioethics education. They are recommended in complex hospital environments to create opportunities that stimulate reflection in the face of the challenges and anxiety caused by complex cases. ${ }^{6}$ In order for them to effectively operate as an instance with educational and support roles to the clinical body on the search for appropriate decision making, the availability and continuous education of its members is required. In the search for better practices, healthcare institutions and physicians need to change their culture and experiences both in relation to mental health and Bioethics. But it is never too late. As Guimarães Rosa wrote in Grande Sertão: Veredas ${ }^{7}$ :

"...Look and see: the most important and beautiful thing in the world is this: that people are not always the same, they are still incomplete - but that they are always changing. In and out of tune. The greatest truth.[...]"

\section{REFERENCES}

1. Martorell LB, Nascimento WF, Garrafa V. Social networks, privacy, confidentiality and ethics: exhibition of pictures of patients on Facebook. Interface. 2016;20(56):13-23.

2. Goldim JR. Bioética: origens e complexidade. Rev HCPA. 2006;26(2):86-92.

3. Bailey R, Jones SM. An integrated model of regulation for applied settings. Clin Child Fam Psychol Rev. 2019;22(1):2-23.

4. Sadock BJ, Sadock VA. Teorias da personalidade e psicopatologia. In: Compêndio de psiquiatria: ciências do comportamento e psiquiatria clínica. 9a ed. Porto Alegre: Artmed;2007. p 221-58.
5. Carvalhal GF, Poli MH, Clementel FK, Gauer GC, Marques GH, Silveira IG, et al. Recomendações para a proteção da privacidade do paciente. Rev Bioét. 2017;25(1):39-43.

6. Conselho Federal de Medicina. Resolução CFM № 8/2015. Recomenda a criação, o funcionamento e a participação dos médicos nos Comitês de Bioética. [cited 2019 Abr 26]. Disponível em: https://sistemas.cfm.org.br/ normas/visualizar/recomendacoes/BR/2015/8

7. Rosa JG. Grande sertão: Veredas. 21ํed. Rio de Janeiro: Nova Fronteira;2015. p.31. 